\title{
Bioethics and physiotherapy
}

\section{loannis Poulis}

\section{Physiotherapy raises serious bioethical questions that are far too little discussed. Concerns include the lack of a clearly defined end point, the closeness of interaction between therapist and patient, the patient's own share of responsibility, and the common failure to refer patients for rehabilitation.}

$\mathrm{P}$ hysiotherapy has evolved dramatically in recent years, to the point where it is now a major healthcare profession offering assessment, diagnosis and treatment for a wide range of conditions, from sports injuries to rehabilitation for major injuries and diseases. According to the World Confederation for Physical Therapy, "Physical Therapy is providing services to people and populations to develop maintain and restore maximum movement and functional ability throughout the lifespan" (p 28). ${ }^{1}$

However, almost uniquely among the healthcare professions, physiotherapy has aroused little or no philosophical interest or engagement. This is surprising, because some of the salient features of physiotherapy raise interesting and to some extent novel problems in ethics. There are, it is true, some papers on ethically related themes, ${ }^{2-5}$ but in comparison with the size of the discipline and the complexity of the problems, the profile of physiotherapy in bioethics is worryingly low.

A first problem is that unlike many areas of medicine-surgery, for example, or radiography or obstetrics and gynaecology-physiotherapy has no obvious end point. In medicine, the end points of treatment are generally well defined, with only a few exceptions, such as plastic surgery or psychiatry. It is my impression that physiotherapy, with few exceptions, does not operate with the concept of end points. (My recent editorial highlights this problem. ${ }^{6}$ ) Although what physiotherapy aims at is clear, the point at which the aims are achieved is uncertain. For example, in many cases the patient would go on benefiting from sessions of physiotherapy, perhaps with diminishing returns but still with some benefit, far beyond the point at which either the healthcare system could pay for the service or the patient could find the stamina to continue. It might be said that it is impossible to have too much physiotherapy and that there is no limit to the benefit that might be obtained from the therapeutic manipulation of damaged tissue or from exercises that strengthen bodily systems. Equally, it is arguable that if the treatment is ended prematurely, it benefits will not be fully achieved.

These features make it difficult to know what an adequate exposure to physiotherapy is or how those responsible for setting limits to treatment arrive at their treatment protocols. For example, is the goal restoration of normal functioning or is it a return to the level of function before the accident or injury? If the patient is a famous sportsman or a professional violinist, is it enough to give the degree of physiotherapy which would suffice for patients used to more modest levels of physical performance?

In physiotherapy there is a close physical relationship between therapist and patient. This sometimes involves touching (doing assisted exercises) and both manipulation and mobilization of the body, as well as massage. In addition, the physiotherapist meets with the patient in a course of treatment usually involving 10 or more sessions, many more than the usual visits to a general practitioner. Since a physiotherapist must continually assess the patient, the degree of communication between the patient and her physiotherapist must be well above the average in order to achieve successful rehabilitation. All these features may create an emotional involvement of the physiotherapist. To date there has been little attention to the ethics of these interactions, or to codes of conduct or of "good practice".

Another interesting feature is that in physiotherapy the patient is seldom a solely passive recipient of treatment. According to McCarthy, in physiotherapy the patient is actively engaged. ${ }^{7}$ This means that the responsibility for the success or failure of the treatment is often shared between therapist and patient to a degree and in a way that does not normally happen in other healthcare professions. For example, in other areas, although patients may retard their progress or damage themselves by reckless behaviour or so-called non-compliance with treatment, they rarely have to take on the role of active therapist for themselves.

In the United Kingdom, in Greece and, I assume, in many other countries, access to physiotherapy, at least as part of publicly funded healthcare, can be difficult. Referral for physiotherapy is not routine, and acute services are often unaware of the necessity to refer patients for physical rehabilition, or even counsel patients as to its advisability. Patients are often left to their own devices with regard to rehabilitation. The extent to which physiotherapy can be legitimately considered inessential in this way raises important issues. Will we see a rise in negligence litigation centred on failure to provide rehabilitation therapy?

Physiotherapy is a new science, inevitably stretching its boundaries and trying to ensure that its practice is evidence based. The American Physical Therapy Association vision statement includes the following assertion: "Research advances the science of physical therapy and furthers the evidence-based practice of the physical therapist." ${ }^{\prime 8}$

An increasing emphasis on research in healthcare has manifested itself through calls for evidence-based practice.' Evidence-based practice is clinical decision-making based on information from three sources: patient values, clinical expertise, and knowledge of the best research evidence. ${ }^{10}$ Manns and Darrah consider the link between the two to be so important that they present ideas for debate about strategies to enhance integration between research and clinical practice in physical therapy. ${ }^{11}$ To decide the scope of research is also a philosophical consideration. Many questions about the enrolment of research subjects or the scope of studies raise ethical issues.

Physiotherapy is primarily concerned with improvement in the quality of life. In this sense, it is not "sexy". Maybe physiotherapy as a subject is "unlucky" in that there have been no highly popular cases like the Terry Schiavo case. ${ }^{12-14}$ Major scandals are rare, and dramatic, life-and-death issues are rarer. Therefore, a dialogue about physiotherapy is difficult to open, leaving physiotherapists with little or no feedback from public opinion. This lack of feedback and criticism carries with it the danger that physiotherapy will become a narrow, introvert profession unaware of what is important and what is not, detached from patients' real needs.

Bioethics and physiotherapy share a common scope: the autonomy of the 
patient. Healthcare is special because of its impact on opportunity, and physiotherapy in particular works towards the independence and the increased autonomy of the patient. ${ }^{15-16}$ As we have seen, it aims to develop, maintain and restore movement and functional ability. By aiming for the welfare of the patient, it liberates the patient and gives her the opportunity to achieve something that matters to her. Bioethics is the tool to answer the ethical problems that emerge in the clinical and research setting, with autonomy being one of its core aims and guiding principles. ${ }^{17-19}$ These two sciences are complementary. If a patient doing physiotherapy is a small child bicycling, bioethics is the parent, who runs beside with love, on a parallel path, making sure that that she doesn't fall and holding her with care. The common scope of bioethics and physiotherapy is the journey, the autonomy, the ability of the small girl to experience the world to the best of her physical potential.

We need the help of bioethicists who address issues in physiotherapy and of physiotherapists who understand better the ethical problems of clinical practice. Physiotherapists must come forward; they must communicate their general thoughts and speculations on case studies that they encounter in clinical practice. Their aim must be to highlight not necessarily a special, difficult case but, rather, everyday problems. Physiotherapists must publish their ethical problems in bioethical journals, which must be open to the problems of physiotherapy.

It is not an accident that international athletes use physiotherapy to minimise damage and maximise the speed of their recovery, but this standard of care is rare for the generality of patients. It is also not simply a cliché when lawyers and human rights specialists say that justice delayed is justice denied. Healthcare in most societies does not routinely provide the physiotherapy early enough and in sufficient measure to ensure that damage is adequately limited and recovery expedited. Thus surely both justice and rescue are denied.

There is a marriage of mutual convenience between the two sciences, a mutual self-interest. Physiotherapy is fertile ground for bioethics, since physiotherapists must protect themselves from of malpractice and must have answers for all ethical conflicts that they encounter. Bioethicists have the chance to do what they know best-that is, protect the parties involved and give right answers to all the problems. The little girl must not fall, must continue bicycling, must be autonomous.

J Med Ethics 2007;33:435-436.

doi: 10.1136/jme.2007.021139

Correspondence to: loannis Poulis, Lecturer in Physiotherapy, Department of Physiotherapy, School of Health and Caring Professions, Technological Educational Institute of Lamia, 3rd $\mathrm{klm}$, Old National Road, Lamia-Athens, 351 00, Lamia, Greece; ipoulis@teilam.gr

Received 27 March 2007

Revised 27 March 2007

Accepted 27 March 2007

Competing interests: None.

\section{REFERENCES}

1 World Confederation for Physical Therapy. Declarations of principle and position statements, http://www.wcpt.org/common/docs/ WCPTPolicies.pdf (accessed 15 July 2007).

2 Sim J. Informed consent: ethical implications for physiotherapy. Physiotherapy 1986;72:584-6.

3 Elkin S, Anderson L. Ethics and physiotherapy: an introduction. NZ J Physiother 1998;26:9-18.

4 Purtilo RB. A time to harvest, a time to sow: ethics for a shiffing landscape [31 st Mary McMillan lecture]. Phys Ther 2000;80:1112-9.

5 Delany C. Informed consent: broadening the focus [editorial]. Aust J Physiother 2003;49:159-61.

6 Poulis I. The end of physiotherapy. Aust J Physiother 2007;53:71-2.

7 Chartered Society of Physiotherapy. Congress 2006-Physiotherapy: an active treatment [report of conference paper by C McCarthy]. http:// www.csp.org.uk/director/newsandevents/ frontline/archiveissues.cfm?ITEM_ID = A34AA657C7091330BA7F28E9427A181E\& article (accessed 25 Jun 2007).

8 American Physical Therapy Association Vision Statement for Physical Therapy 2020 (Vision 2020). Alexandria, Va: APTA, 2000; http://www.apta. org/AM/Template.cfm?Section = Archives2\& Template $=/$ Customsource/TaggedPage/PTIssue . cfm\&lssue = 06/24/2003 (accessed 15 July 2007).

9 Bury T, Mead J. Evidence based healthcare: a practical guide for therapists. Oxford: Butterworth-Heinemann, 1998.

10 Sackett D, Straus SE, Richardson WS, et al. Evidencebased medicine: how to practice and teach EBM, 2nd ed. Edinburgh: Churchill Livingstone, 2000.

11 Manns PJ, Darrah J. Linking research and clinical practice in physical therapy: strategies for integration. Physiotherapy 2006;92:88-94

12 Caplan AL, McCartney JJ, Sisti DA, eds. The case of Terri Schiavo: ethics at the end of life. Amherst, NY: Prometheus Books, 2006.

13 Koch T. The challenge of Terri Schiavo: lessons for bioethics. J Med Ethics 2005;31:376-8.

14 Sulmasy DP. Terri Schiavo and the Roman Catholic tradition of forgoing extraordinary means of care. $J$ Law Med Ethics 2005;33:359-62.

15 Daniels N. Health-care needs and distributive justice. Philos Public Aff 1981;10:146-179.

16 Daniels N. Just healthcare. New York: Cambridge University Press, 1985.

17 Mill JS. On liberty and other writings. Collini S, ed. Cambridge: Cambridge University Press, 1989:1-116.

18 Dworkin R. Life's dominion: an argument about abortion and euthanasia. London: HarperCollins, 1995:224.

19 Beauchamp TL, Childress JF. Principles of biomedical ethics, 5th edn, chapter 3. New York: Oxford University Press, 2002:57-112.

\section{BNF for Children 2006, second annual edition}

In a single resource:

- guidance on drug management of common childhood conditions

- hands-on information on prescribing, monitoring and administering medicines to children

- comprehensive guidance covering neonates to adolescents

For more information please go to bnfc.org 